\title{
Analisa Metode Least Significant Bit Dalam Penyisipan Pesan Terenkripsi Terhadap Citra Digital
}

\author{
Penda Sudarto Hasugian \\ Teknik Informatika, STMIK Pelita Nusantara Medan, Jl. Iskandar Muda No.1 Medan \\ Email : penda.hasugian@gmail.com
}

\begin{abstract}
Berkembangnya jaringan komunikasi membuat pertukaran informasi semakin sering terjadi, baik dalam bentuk teks, audio, dan video. Semakin banyaknya pesan yang yang ingin dikirimkan maka keamanan dan kerahasiaan dari pesan tersebut semakin sulit dijaga. Keamanan dan kerahasiaan adalah aspek yang penting pada proses pertukaran informasi atau pesan. Untuk melindungi kerahasiaan pesan bisa menggunakan teknik kriptografi. Kriptografi adalah ilmu yang mempelajari teknik - teknik matematika yang berhubungan dengan aspek keamanan seperti kerahasiaan, integritas data, serta otentikasi. Sedangkan Steganografi adalah salah satu teknik yang dilakukan dalam mengamankan pesan yaitu dengan cara menyembunyikan pesan ke sebuah media digital. Pada penelitian ini dilakukan analisis untuk mengimplementasikan keamanan file txt dan rtf dengan kombinasi algoritma kriptografi One Time Pad dengan steganografi least significant bit (LSB). Pada tahap kriptografi pesan yang telah berhasil diinput akan dienkripsi dengan kunci yang telah diberikan kemudian dilanjutkan dengan proses penyisipan pesan di tahap steganografi.. Pesan yang dapat dibaca oleh sistem adalah pesan berformat .txt dan .rtf. Pada Algoritma LSB penyisipan dilakukan dengan menggantikan bit terakhir citra dengan bit pesan yang akan disisipkan. Pada tahap enkripsi dan penyisipan akan dihasilkan stego image, stego image merupakan citra yang sudah disisip oleh pesan. Kemudian pada tahap ekstraksi dan dekripsi yang dihasilkan adalah plaintext, plaintext merupakan pesan yang belum diberikan kunci apapun.
\end{abstract}

\section{Pendahuluan}

Seiring berkembangnya media internet dan aplikasi yang menggunakan internet semakin betambah pula kejahatan dalam sistem informasi. Caranya yaitu dengan menggunakan image, sound maupun video dalam menyembunyikan informasi rahasia di dalam suatu wadah penampung informasi dengan sedemikian rupa, sehingga keberadaan informasi rahasia yang sisipkan tidak terlihat. Wadah penampung rahasia tersebut dapat berbentuk berbagai jenis file multmedia digital seperti teks, citra, audio dan video Oleh karena itu, digunakan steganografi dengan menerapkan metode Least Significant Bit sebagai teknik yang digunakan menyembunyikan informasi yang berupa nilai-nilai bit. Bit-bit data yang akan disembunyikan atau diamankan dengan Least Significant Bit ke dalam media pesan. Setelah di analisa dan diimplementasikan maka, diperoleh bahwa nilainilai bit yang disisipkan ke dalam media pesan masih tampak seperti normal sehingga tidak menimbulkan kecurigaan bagi orang yang mebaca. One Time Pad adalah merupakan salah satu algoritma kriptografi kunci simetris. Algoritma One Time Pad m sebagai kunci untuk melakukan enkripsi dan dekripsi. Dasar teori matriks yang digunakan dalam One Time Pad antara lain adalah perkalian antar matriks dan melakukan invers pada matriks. Diseluruh dunia internet sudah berkembang menjadi salah satu media komunikasi data yang sangat populer. Kemudahan dalam pengunaan dan fasilitas yang sangat lengkap merupakan keunggulan yang dimiliki oleh internet dan bukan rahasia umum dikalngan masyarakat mengguna inetrnet pada saat sekarang ini.

\section{Landasan Teori}

\subsection{Metode Least Significant Bit}

Steganografi mempunyai 2 metode, yaituMost Significant Bit (MSB)dan Least Significant Bit (LSB). Untuk Most Significant Bit adalah sebuah metode penyisipan dengan cara menggantinilai bit-bit atas dari data media penampung dengan nilai bit-bit dari data yang akandisembunyikan. Sedangkan Least Significant Bit adalah kebalikan dari Most Significant Bit, yaitu sebuah metode menyembunyikan data pada bit bawah (LSB) pada data pixel yang menyusun file tersebut (Stalling,2003).

Metode Most Significant Bit hanya mampu menyimpan informasi dengan ukuran terbatas. Seperti untuk file atau citra bitmap 24 bit maka setiap pixel (titik) pada gambar tersebut terdiri dari susunan tiga warna merah, hijau dan biru (RGB) yang masing masing disusun oleh bilangan 8 bit (byte) Dari 0 sampai 255 atau dengan format biner 00000000 sampai 11111111. Dengan demikian pada setiap pixel file bitmap 24 Bit dapat menyisipkan 3 bit data.

Contohnya Huruf A Dapat disisipkan dalam 3 pixel, 
Misalnya data raster original adalah sebagai berikut:

$00100111 \quad 1101001111001000$

R G B

Sedangkan representasi biner huruf A adalah 01100001. Dengan menyisipkan 4 bit kedalam nilai R dan 4 bit kedalam nilai B pada pixel diatas dengan menggunakan metode LSB maka akan dihasilkan:

$\mathrm{R}$ awal $=00100111$, setelah disisipkan 4 bit dari kiri 0110 .

Maka R baru $=00100110$.

$\mathrm{B}$ awal $=11001000$, setelah disisipkan 4 bit dari kiri 0001 .

Maka B baru $=11000001$.

Terlihat hanya empat bit rendah yang berubah, sehingga untuk mata manusia tidak akan tampak perubahannya.

\subsection{Kriptografi}

Kriptografi berasal dari bahasa Yunani, menurut bahasa dibagi menjadi dua kripto dan graphia, kripto berarti secret (rahasia) dan graphia berarti writing (tulisan). Menurut teminologinya kriptografi adalah ilmu dan seni untuk menjaga keamanan pesan ketika pesan dikirim dari satu tempat ke tempat lain[7].

\subsection{Algoritma One Time Pad}

One time pad termasuk dalam kelompok kriptografi simestris. One-time pad ( pad = kertas bloknot) berisi deretan karakter-karakter kunci yang dibangkitkan secara acak. Cipher ini diimplementasikan melalui sebuah kunci yang terdiri dari sekumpulan random karakter-karakter yang tidak berulang (Munir, 2007 ). Setiap huruf kunci dijumlahkan modulo 26 dengan huruf pada plaintext. Pada One Time Pad, tiap huruf kunci digunakan satu kali untuk satu pesan dan tidak digunakan kembali.Panjang stream karakter kunci sama dengan panjang pesan.Satu-satunya algoritma kriptografi yang tidak dapat dipecahkan adalah one time pad. One-Time Pads (OTP).One time pad ditemukan pada tahun 1917 oleh Major Joseph Mauborgne. Cipher ini termasuk ke dalam kelompok algoritma kriptografi simetri. One time pad ( pad = kertas bloknot) berisi barisan karakter-karakter kunci yang dibangkitkan secara acak. Aslinya, satu buah one time pad adalah sebuah pita (tape) yang berisi barisan karakter-karakter kunci. Satu pad hanya digunakan sekali (one time) saja untuk mengenkripsi pesan, setelah itu pad yang telah digunakan dihancurkan supaya tidak dipakai kembali untuk mengenkripsi pesan yang lain. Aturan enkripsi yang digunakan persis sama seperti pada CipherVigenere. Pengirim pesan menggunakan setiap karakter kunci untuk mengenkripsikan satu karakter plainteks. Enkripsi dapat digambarkan sebagai penjumlahan modulo 26 dari satu karakter plainteks dengan satu karakter kunci one time pad :Adapun rumus enkripsi (sumber : Munir, 2007 ) adalah sebagai berikut :

$$
\mathrm{Ci}=(\mathrm{Pi}+\mathrm{Ki}) \operatorname{Mod} 26
$$

Keterangan :

Pi : karakter plainteks

$\mathrm{Ki}$ : karakter kunci

$\mathrm{Ci}$ : karakter Cipherteks

Sedangkan rumus dekripsi dapat dilihat pada rumus dibawah ini

$\mathrm{Pi}=(\mathrm{Ci}-\mathrm{Ki}) \bmod 26$ untuk $\mathrm{Ci}>=\mathrm{Ki}$

$\mathrm{Pi}=(\mathrm{Ci}+26-\mathrm{Ki}) \bmod 26$ untuk $\mathrm{Ci}<=\mathrm{Ki}$

Keterangan :

$\mathrm{Pi}$ : karakter plainteks

$\mathrm{Ki}$ : karakter kunci

Ci : karakter Cipherteks

Suatu algoritma dikatakan aman, apabila belum ada tidak ada cara untukmenemukan plaintext-nya. Sampai saat ini, hanya algoritma One Time Pad (OTP) yang dinyatakan tidak dapat dipecahkan meskipun diberikan sumber daya yang tidak terbatas. Prinsip enkripsi pada algoritma ini adalah dengan mengkombinasikan masingmasing karakter pada plaintext dengan satu karakter pada kunci. Oleh karena itu, panjang kunci setidaknya harus sama denganpanjang plaintext. Secara teori, adalah hal yang tak mungkin untuk mendeskripsi chipertext tanpa mengetahui kuncinya. Sebab jika kunci yang digunakan salah, akan diperoleh hasil yang salah juga, atau bukan plaintext yang seharusnya. Kemudian setiap kuncinya hanya boleh digunakan untuk sekali pesan. Pengambilan kunci harus dilakukan secara acak supaya tidak dapat diterka lawan dan jumlah karakter kunci harus sebanyak jumlah karakter pesan. 


\section{Analisa}

\subsection{Penerapan LSB}

\section{Proses Enkripsi Dan Penyisipan}

Sebagai contoh kita akan mengamankan pesan dengan isi karakternya adalah "PENDA". Proses pengamanan pesan dapat dilihat pada langkah-langkah berikut ini:

1. Masukkan pesan, format yang bisa dibaca adalah txt dan rtf. Misalkan pesan yang akan dimasukkan adalah format .txt dengan isi teksnya adalah PENDA".

2. Masukkan kunci untuk melakukan enkripsi dengan maksimal 20 huruf, adapun kunci yang digunakan yaitu MAKAN

3. Masukkan citra dengan format bmp, kemudian citra akan diresize menjadi 300x300 piksel.

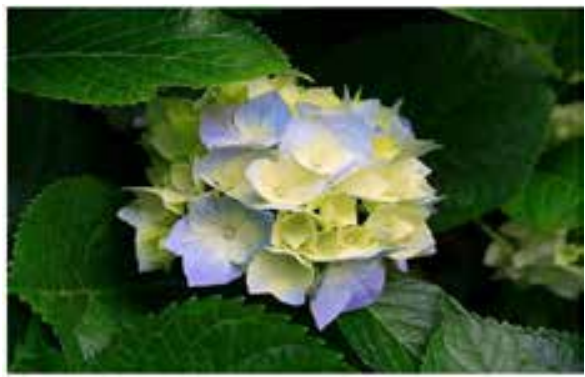

Gambar 1. Citra yang akan disisip

4. Pesan akan dienkripsi dengan kunci yang dibuat. Pesan akan dikonverikan kedalam table. Nilai pesan asli dan kunci dapat dilihat pada Tabel 1 dibawah ini.

Tabel 1 : Tabel Utama

\begin{tabular}{|l|l|l|l|l|l|l|}
\hline $\mathbf{A}$ & $\mathbf{B}$ & $\mathbf{C}$ & $\mathbf{D}$ & $\mathbf{E}$ & $\mathbf{F}$ & $\mathbf{G}$ \\
\hline 0 & 1 & 2 & 3 & 4 & 5 & 6 \\
\hline $\mathbf{H}$ & $\mathbf{I}$ & $\mathbf{J}$ & $\mathbf{K}$ & $\mathbf{L}$ & $\mathbf{M}$ & $\mathbf{N}$ \\
\hline 7 & 8 & 9 & 10 & 11 & 12 & 13 \\
\hline $\mathbf{O}$ & $\mathbf{P}$ & $\mathbf{Q}$ & $\mathbf{R}$ & $\mathbf{S}$ & $\mathbf{T}$ & $\mathbf{U}$ \\
\hline 14 & 15 & 16 & 17 & 18 & 19 & 20 \\
\hline $\mathbf{V}$ & $\mathbf{W}$ & $\mathbf{X}$ & $\mathbf{Y}$ & $\mathbf{Z}$ & & \\
\hline 21 & 22 & 23 & 24 & 25 & & \\
\hline
\end{tabular}

Tabel 2. Tabel Konversi Alphabet Ke Nilai One Time Pad

\begin{tabular}{|l|l|l|l|l|l|}
\hline \multirow{2}{*}{ Pesan } & $\mathrm{P}$ & $\mathrm{E}$ & $\mathrm{N}$ & $\mathrm{D}$ & $\mathrm{A}$ \\
\cline { 2 - 6 } & 15 & 4 & 13 & 3 & 0 \\
\hline \multirow{2}{*}{ Kunci } & $\mathrm{M}$ & $\mathrm{A}$ & $\mathrm{K}$ & $\mathrm{A}$ & $\mathrm{N}$ \\
\cline { 2 - 6 } & 12 & 0 & 10 & 0 & 13 \\
\hline
\end{tabular}

Setelah mendapatkan nilai dari pesan asli dan nilai dari kunci maka kita akan melakukan proses enkripsi dengan menggunakan rumus : $\mathrm{C}_{\mathrm{i}}=\left(\mathrm{P}_{\mathrm{i}}+\mathrm{K}_{\mathrm{i}}\right) \bmod 26$

Tabel 3. Tabel Hasil Enkripsi

\begin{tabular}{|c|c|l|c|c|}
\hline Nilai Plaintext & Nilai Kunci & $\mathrm{Ci}=(\mathrm{Pi}+\mathrm{Ki}) \operatorname{Mod} 26$ & Nilai Chipertext & Chipertext \\
\hline 15 & 12 & $(15+12) \bmod 26$ & 1 & $\mathrm{~B}$ \\
\hline 4 & 0 & $(4+0) \bmod 26$ & 4 & $\mathrm{E}$ \\
\hline 13 & 10 & $(13+10) \bmod 26$ & 23 & $\mathrm{X}$ \\
\hline 3 & 0 & $(3+0) \bmod 26$ & 13 & $\mathrm{D}$ \\
\hline 0 & 13 & $(0+13) \bmod 26$ & $\mathrm{~N}$ \\
\hline
\end{tabular}


Nilai karakter ciphertext BEXDN akan disesuaikan dengan nilai karakter pada table ASCII, dan kemudian akan dikonversikan ke bilangan biner.
B : 01000010
$\mathbf{E}: 01000101$
$\mathbf{X}: 01011000$
D : 01000100
$\mathbf{N}: 01001110$

Setelah mendapat bilangan binernya pesan akan disisipkan kedalam file citra. Citra yang diinput akan dibaca nilai piksel- pikselnya.

Tabel 4. Nilai Piksel Citra

\begin{tabular}{|l|l|l|l|l|l|l|l|l|}
\hline $\mathrm{R}$ & $\mathrm{G}$ & $\mathrm{B}$ & $\mathrm{R}$ & $\mathrm{G}$ & $\mathrm{B}$ & $\mathrm{R}$ & $\mathrm{G}$ & $\mathrm{B}$ \\
\hline 100 & 110 & 25 & 86 & 134 & 41 & 34 & 136 & 52 \\
\hline 183 & 80 & 20 & 130 & 74 & 15 & 19 & 149 & 65 \\
\hline 150 & 41 & 19 & 140 & 124 & 30 & 100 & 132 & 45 \\
\hline 198 & 63 & 19 & 197 & 67 & 27 & 150 & 64 & 22 \\
\hline 156 & 49 & 15 & 175 & 24 & 16 & 15 & 50 & 53 \\
\hline 125 & 75 & 35 & 180 & 86 & 31 & 180 & 40 & 25 \\
\hline 95 & 80 & 21 & 162 & 80 & 25 & 185 & 25 & 15 \\
\hline 64 & 97 & 25 & 130 & 64 & 14 & 180 & 19 & 18 \\
\hline
\end{tabular}

Kemudian penyisipan akan dilakukan dengan mengganti nilai bit terakhir dengan nilai bilangan biner pesan.

Tabel 5. Nilai Biner Piksel Citra dan Proses Penyisipan Pesan

\begin{tabular}{|c|c|c|c|c|c|c|c|c|}
\hline$\overline{\mathrm{R}}$ & G & B & $\mathbf{R}$ & G & B & $\overline{\mathrm{R}}$ & G & B \\
\hline 011001 & 011011 & 000110 & 010101 & 100001 & 001010 & 001000 & 100010 & 001101 \\
\hline 00 & 10 & 01 & 10 & 10 & 01 & 10 & 00 & 00 \\
\hline $\begin{array}{l}101101 \\
11\end{array}$ & $\begin{array}{l}010100 \\
00\end{array}$ & $\begin{array}{l}000101 \\
00\end{array}$ & $\begin{array}{l}100000 \\
10\end{array}$ & $\begin{array}{l}010010 \\
10\end{array}$ & $\begin{array}{l}000011 \\
11\end{array}$ & $\begin{array}{l}000100 \\
11\end{array}$ & $\begin{array}{l}100101 \\
01\end{array}$ & $\begin{array}{l}010000 \\
01\end{array}$ \\
\hline 100101 & 010100 & 000100 & 100011 & 011111 & 000111 & 011001 & 100001 & 001011 \\
\hline 10 & 10 & 11 & 00 & 00 & 10 & 00 & 00 & 01 \\
\hline $\begin{array}{l}110001 \\
10\end{array}$ & $\begin{array}{l}001111 \\
11\end{array}$ & $\begin{array}{l}000100 \\
11\end{array}$ & $\begin{array}{l}110001 \\
01\end{array}$ & $\begin{array}{l}010000 \\
11\end{array}$ & $\begin{array}{l}000110 \\
11\end{array}$ & $\begin{array}{l}100101 \\
10\end{array}$ & $\begin{array}{l}010000 \\
01\end{array}$ & $\begin{array}{l}000101 \\
10\end{array}$ \\
\hline $\begin{array}{l}100111 \\
00\end{array}$ & $\begin{array}{l}001100 \\
01\end{array}$ & $\begin{array}{l}000011 \\
11\end{array}$ & $\begin{array}{l}101011 \\
11\end{array}$ & $\begin{array}{l}000110 \\
00\end{array}$ & $\begin{array}{l}000110 \\
01\end{array}$ & $\begin{array}{l}000011 \\
11\end{array}$ & $\begin{array}{l}001100 \\
11\end{array}$ & $\begin{array}{l}001101 \\
01\end{array}$ \\
\hline $\begin{array}{l}011111 \\
01\end{array}$ & $\begin{array}{l}010010 \\
11\end{array}$ & $\begin{array}{l}001000 \\
11\end{array}$ & $\begin{array}{l}101101 \\
00\end{array}$ & $\begin{array}{l}010101 \\
10\end{array}$ & $\begin{array}{l}000110 \\
01\end{array}$ & $\begin{array}{l}101101 \\
00\end{array}$ & $\begin{array}{l}001010 \\
00\end{array}$ & $\begin{array}{l}000110 \\
01\end{array}$ \\
\hline $\begin{array}{l}010111 \\
11\end{array}$ & $\begin{array}{l}010100 \\
00\end{array}$ & $\begin{array}{l}000101 \\
01\end{array}$ & $\begin{array}{l}101000 \\
10\end{array}$ & $\begin{array}{l}010100 \\
00\end{array}$ & $\begin{array}{l}000110 \\
01\end{array}$ & $\begin{array}{l}101110 \\
01\end{array}$ & $\begin{array}{l}000110 \\
00\end{array}$ & $\begin{array}{l}000011 \\
11\end{array}$ \\
\hline 010000 & 011000 & 000110 & 100000 & 010000 & 000011 & 101101 & 000100 & 000100 \\
\hline 00 & 01 & 01 & 10 & 00 & 10 & 00 & 10 & 10 \\
\hline
\end{tabular}

Hasil Penyisipan Hasil Enkripsi Dengan Citra

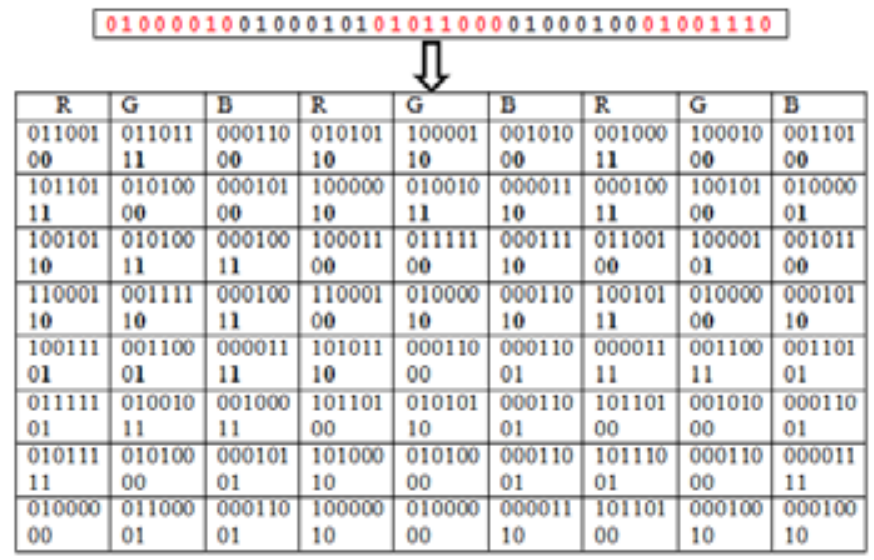




\section{Algoritma}

\subsection{Algoritma Enkripsi}

Adapun algoritma yang digunakan dalam proses enkripsi ini adalah sebagai berikut :

$\begin{array}{ll}\text { Algoritma Enkripsi } \\ \text { Deklarasi } & : \mathrm{K}_{\mathrm{i}}, \mathrm{P}_{\mathrm{i}} \mathrm{C}_{\mathrm{i}} \text { as string } \\ \text { Input } & : \mathrm{K}_{\mathrm{i}} \otimes \text { kunci } \\ & : \mathrm{P}_{\mathrm{i}} \text { \pesan } \\ \text { Output } & : \mathrm{C}_{\mathrm{i}} \otimes \text { Chipertext } \\ \text { Proses } & : \text { mulai } \\ & \mathrm{C}_{\mathrm{i}}=\left(\mathrm{P}_{\mathrm{i}}+\mathrm{K}_{\mathrm{i}}\right) \bmod 26 \\ & \text { Selesai }\end{array}$

\subsection{Algoritma Penyisipan}

Adapun algoritma penyisipan pesan dan image adalah sebagai berikut:

Algoritma Dekripsi Penyisipan

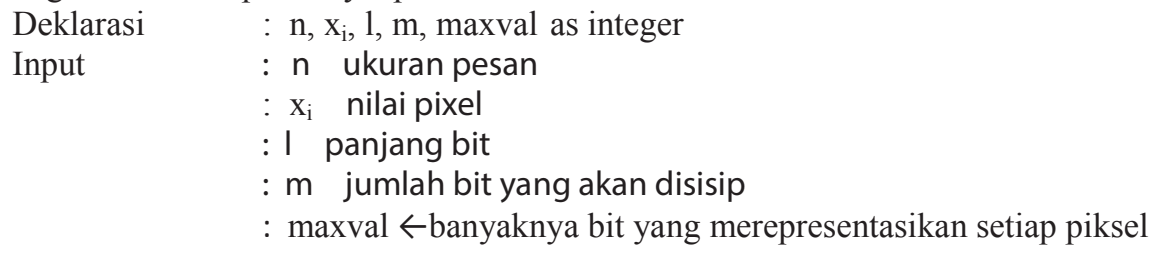

Output $\quad: \mathrm{x}_{\mathrm{j}} \otimes$ hasil penyisipan gambar dan pesan

Proses : mulai

$$
\begin{aligned}
& \text { for } \mathrm{i}=1 \text { to } \mathrm{n} \text { do } \\
& \mathrm{x}_{\mathrm{i}}=\mathrm{x}+\mathrm{e}_{\mathrm{i}}-\left(\operatorname{LSB}_{\mathrm{m}}\left(\mathrm{x}_{\mathrm{i}}-1\right) \bmod 2^{\mathrm{m}}\right. \\
& \text { if } \mathrm{x}_{\mathrm{i}}>\operatorname{maxval} \text { then } \\
& \text { end } \quad \mathrm{x}_{\mathrm{i}}=\mathrm{x}_{\mathrm{i}}-2^{\mathrm{m}} \\
& \text { if } \mathrm{x}_{\mathrm{i}}>\text { maxval then } \\
& \text { end } \quad \mathrm{x}_{\mathrm{i}}=\mathrm{x}_{\mathrm{i}}+2^{\mathrm{m}}
\end{aligned}
$$

selesai

\section{Kesimpulan}

Setelah menyelesaikan perancangan aplikasi steganografi dengan metode least significant bit dan One time pad, maka penulis dapat mengambil beberapa kesimpulan sebagai berikut :

1. Least Significant Bit, yaitu suatu metode steganografi untuk mendeteksi ada tidaknya pesan rahasia yang disisipkan secara Least Significant Bit pada sebuah citra digital.

2. Cara kerja metode enhanced Least Significant Bit adalah dengan mengubah nilai setiap bit pada suatu byte pixel data citra bitmap menjadi 0 atau 255 sesuai dengan nilai bit Least Significant Bit yang telah diganti dengan bit pesan pada citra digital tersebut.

\section{Referensi}

[1]. Indrajani, S.Kom, MM. 2011. Perancangan Basis Data Dalam Allin1. Elex Media. Komputindo. Jakarta

[2]. Priyanto, Rahmat., 2009, Langsung Bisa Visual Basic.Net 2008, Penerbit ANDI, Yogyakarta

[3]. Rinaldi Munir, 2007, "Belajar Ilmu Kriptografi" Penerbit Andi, Yogyakarta

[4]. Jogiyanto, Hartono. Analisis dan Desain Sistem Informasi, Edisi III. Yogyakarta: ANDI.2008

[5]. Adi Nugroho, 2010, Nugroho Adi. Rekayasa Perangkat Lunak Berorientasi Objek Dengan Metode USDP. Yogyakarta: Andi

[6]. Badudu J.S dan Zain, Sutan Mohammad, 2006, Kamus Umum Bahasa Indonesia. Jakarta: Pustaka Sinar Harapan.

[7]. Lahagu, A. S., \& Hutahaean, H. D. (2017). Perancangan Kios Buku Online Dengan Menerapkan Algoritma MD5 Dalam Pengamanan Record Login. MEANS (Media Informasi Analisa dan Sistem), 2(1), 23-28. 